\title{
Spans attributed to short-term memory are explained by sensitivity to long- term statistics in both musicians and individuals with dyslexia
}

Eva Kimela*, Atalia Hai Weissb, Hilla Jakobyb, Luba Daikhinb, and Merav Ahissara,b

a. The Edmond and Lily Safra Center for Brain Sciences and Department of

Psychology, The Hebrew University of Jerusalem, Edmond J. Safra Campus, Jerusalem 9190401, Israel.

b. Department of Psychology, The Hebrew University of Jerusalem, Edmond J. Safra Campus, Jerusalem 9190401, Israel.

* Correspondence should be addressed to Eva Kimel, eva.kelman@mail.huji.ac.il.

\begin{abstract}
Reduced short-term memory (STM) of individuals with dyslexia (IDDs) and enhanced STM of musicians are well documented, yet their causes are disputed. We hypothesized that their STMs reflect their sensitivities to accumulative long-term stimuli statistics. Indeed, when performing an STM task, IDDs had reduced benefit from syllable frequency, whereas musicians manifested an opposite effect, compared to controls. Interestingly, benefit from sequence-repetition did not significantly differ between groups, suggesting that it relies on different mechanisms. To test the generality of this separation across populations, we recruited a group of good-readers, whose native language contains a smaller fraction of the high-frequency syllables. Their span for these "high-frequency" syllables was small, yet their benefit from sequence-repetition was adequate. These experiments indicate that sensitivity to long-term stimuli distribution, and not to sequential repetition, is reduced in IDDs and enhanced in musicians, and this accounts for differences in their STM performance.
\end{abstract}

Keywords: statistical learning, short-term memory, long-term memory, dyslexia, musicians 


\section{The effective capacity of STM is sensitive to item frequency}

The capacity of our short-term memory (STM) is limited, ranging from the classic estimation of 7 items (“magical number 7 2 ", Miller, 1956) to the more recent suggestion of 4 items ("magical 4 4 ", Cowan, 2010). The most common procedure for measuring STM is the Span Task, in which a participant is asked to reproduce a sequence of items in the order of their presentation. Many studies have found that the item characteristics greatly affect performance in these tasks. For example, spans of frequent words are larger than those of infrequent ones (Hulme et al., 1997; Roodenrys, Hulme, Lethbridge, Hinton, \& Nimmo, 2002), and span for words is greater than for non-words (Hulme, Maughan, \& Brown, 1991). The benefit of familiarity applies also at the syllabic level. Syllable spans are typically assessed with a slightly different task: non-word repetition (e.g. Gathercole \& Adams, 1993 in 2-3 year old children; Susan E Gathercole \& Baddeley, 1989; Susan E Gathercole, Frankish, Pickering, \& Peaker, 1999). For example, Nimmo and Roodenrys (Nimmo \& Roodenrys, 2002) showed that both non-word repetition accuracy and recall of syllable sequences are higher for syllables that occur more frequently in polysyllabic English words. Similarly, Tremblay and colleagues found that non-word repetition accuracy is greater when the frequency of their first syllable is high (Tremblay, Deschamps, Baroni, \& Hasson, 2016).

\section{IDDs are considered to have reduced STM capacity and have reduced utilization of}

\section{implicit prior knowledge}

Developmental dyslexia is defined as a specific difficulty in "accurate or fluent word recognition, poor decoding, and poor spelling abilities" (American Psychiatric Association, 2013), in spite of adequate hearing levels, normal intelligence and adequate educational opportunities. Beyond reading difficulties, of individuals with dyslexia (IDDs) have substantial difficulties in phonological awareness and in span tasks (Jeffries \& Everatt, 2004; 


\section{STM IN MUSICIANS AND DYSLEXIA}

Roodenrys \& Stokes, 2001; Snowling, Goulandris, Bowlby, \& Howell, 1986; Snowling, 1981, though see Wimmer, 1993).

Traditional theories of dyslexia attributed these difficulties to a core deficit in phonological representations (e.g. Snowling, 2000), or reduced efficiency in accessing these representations (Ramus, 2014; Ramus \& Szenkovits, 2008). However, more recent theories, such as the "anchoring deficit hypothesis" (Ahissar, 2007; Ahissar, Lubin, Putter-Katz, \& Banai, 2006) have proposed a learning-related core deficit: reduced sensitivity to stimulus statistics, in spite of adequate sensory processes (Jaffe-Dax, Raviv, Jacoby, Loewenstein, \& Ahissar, 2015). Specifically, IDDs’ memory traces decay faster (Jaffe-Dax, Frenkel, \& Ahissar, 2017; Jaffe-Dax, Kimel, \& Ahissar, 2018; Lieder et al., 2019), yielding a functional "leakage" of memory traces, a consequent reduced learning rate, and hence poorer long-term representations (Banai \& Ahissar, 2017). This hypothesis has some overlap with the phonological account - since phonological representations under this account are also expected to be somewhat impoverished. But, the predictions of this account are not specific to phonology, and in some cases it bears opposite predictions; learning-related deficit theories, as opposed to perceptually-based deficits, predict that relative difficulties are expected to increase with stimulus-specific exposure. Deficits associated with linguistic regularities, such as morphological deficits, have been reported in several studies (Rispens, Roeleven, \& Koster, 2004; Schiff \& Ravid, 2007). For example, IDDs have been shown to have a reduced morphological benefit in acquiring new words (Kimel \& Ahissar, 2019). This learning deficit hypothesis leads us to expect an increase in relative difficulties with increased exposure, due to the reduced rate of learning of regularities and repetitions in the input. Given the evidence of substantial influence of item frequency on the performance in span tasks, we now ask whether IDDs' reduced sensitivity to language statistics can explain one of IDDs' most reliably reported characteristics - their reduced STM. 


\section{Musicians are considered to have increased STM capacity and have enhanced utilization of implicit prior knowledge}

There is ample evidence that musical proficiency is correlated with performance in STM tasks in the domain of language (Chen, Penhune, \& Zatorre, 2008b, 2008a; Janata \& Grafton, 2003; Janata, Tillmann, \& Bharucha, 2002). For example, children and adults who have received musical training have been shown to outperform non-musicians on digit and non-word span tasks (Franklin et al., 2008; Fujioka, Ross, Kakigi, Pantev, \& Trainor, 2006; Lee, Lu, \& Ko, 2007; Parbery-Clark, Skoe, Lam, \& Kraus, 2009, Chandrasekaran \& Kraus, 2010).

In separate, seemingly unrelated studies, it has been found that musicians' show enhanced performance in statistical learning tasks (Shook, Marian, Bartolotti, \& Schroeder, 2013). We hypothesize that musicians' enhanced STM is actually a manifestation of an improved utilization of long-term stimulus statistics, which beneficially impacts their ability to benefit from exposure.

\section{Sensitivity to stimulus statistics is expected to affect learning rate}

We thus hypothesize that both IDDs' poor STM and musicians' elevated STM are a consequence of their relative sensitivities to long-term item statistics, specifically stimulus frequency. Figure 1 is a schematic illustration of this hypothesis and its predictions. The main underlying principle is that cumulative benefits from encounters with stimuli, i.e. learning rate, are affected by sensitivity to stimuli statistics (e.g. in the case of IDDs, sensitivity is reduced due to faster memory decay, and hence learning rate is decreased). Importantly, though learning rate decreases with exposure (learning curve is convex), it does not saturate, and improvement continues for years. This continuous learning has been shown across domains (the exponential/power law of practice - Crossman, 1959; Heathcote, Brown, \& 
Mewhort, 2000), and, among others, applies to reading. Thus, although the reading rate of IDDs continuously improves with practice, they (typically) do not catch up with their peers. This basic conceptualization yields a simple, yet not intuitive prediction, as illustrated in Figure 1. Although all groups improve with practice, the group differences in performance will increase with greater practice and exposure (right hand side of Figure 1). Therefore, compared to controls with a similar exposure, IDDs' STM will be particularly poor for frequent items, whereas musicians' STM will be particularly high.

As our stimuli we chose frequent and infrequent syllables. We chose to focus on syllables as their familiarity is not strongly dependent on reading experience; they usually do not carry semantic content in Hebrew; and there is evidence of their presence as separate mental entities quite early in development (e.g. Perfetti, Beck, Bell, \& Hughes, 1987). Thus, illiterate adults and nursery-school children show similar success rates in manipulating syllables, but only literate individuals successfully operate with phonemes (Liberman, Shankweiler, Fischer, \& Carter, 1974; Morais, Cary, Alegria, \& Bertelson, 1979). As frequent syllables, we chose Consonant-Vowel (CV) syllables, and as infrequent we chose Vowel-Consonant (VC) syllables. CV syllables are part of the syllabic vocabulary in almost all known languages (Sommer, 1970). They are acquired early and predominate both in babbling and in early meaningful speech (Stoel-Gammon, 1989). In Hebrew they constitute the majority of syllables (Ben-Dror, Frost, \& Bentin, 1995). Contrary to CV syllables, VC syllables are rare in languages in general (Clements \& Keyser, 1983). In Hebrew VC syllables are an order of magnitude less frequent than CV syllables (Ben-Dror et al., 1995; discussed in Share \& Blum, 2005). 


\section{STM IN MUSICIANS AND DYSLEXIA}

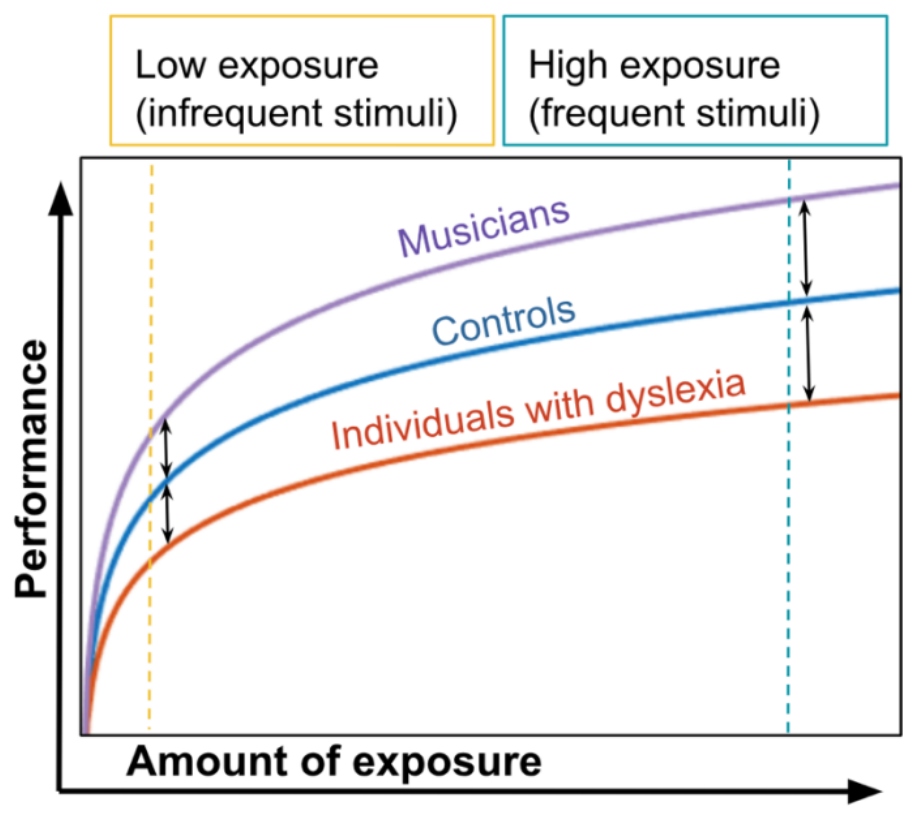

Figure 1. A schematic illustration of expected performance in span tasks as a function of exposure to the tested stimuli in 3 populations with different sensitivities to stimuli statistics. All participants start from scratch (zero performance) and improve, with no saturation (e.g. log function). Therefore, group difference is expected to increase with exposure, and be larger for high-frequency items (blue dashed line on the right) compared with low-frequency items (orange dashed line on the left). To test the impact of item frequency, we measured spans of two syllable types, frequent and infrequent, respectively.

\section{Experiment 1}

We measured spans of frequent (CV) and infrequent (VC) syllables in 3 populations: IDDs, controls and musicians (selection criterions are detailed in the method section). Based on previous studies, mean spans were expected to be higher for frequent than infrequent syllables; overall performance of IDDs was expected to be lower than that of the control group; musicians' performance was expected to be higher than controls'. Crucially, we predict a previously unattested interaction: syllabic frequency would benefit musicians more than controls, but aid IDDs to a lesser extent. 


\section{STM IN MUSICIANS AND DYSLEXIA}

Span scores also benefit from sequence repetition (serial-order repetition). Importantly, some studies (Bogaerts, Szmalec, Hachmann, Page, \& Duyck, 2015; Szmalec, Loncke, Page, \& Duyck, 2011; though see Henderson \& Warmington, 2017; Staels \& Van den Broeck, 2014, 2015;Wang, Xuan, \& Jarrold, 2016) have found that IDDs benefit less from serial-order repetition, and this might account for IDDs' reduced spans (and hence also account for musicians' increased spans). We therefore also assessed benefits from serialorder repetition in the same task. Assessing the specific advantage afforded by repetition of the same series, for each type of syllables (CV and VC) separately, provided a separate estimate for repeated series learning.

\section{Method}

General cognitive assessments

Non-verbal intelligence was assessed using the Block Design task (a subtest from the Hebrew version of the Wechsler Adult Intelligence Scale, WAIS-III; Wechsler, 1997). The Block Design task measures spatial reasoning abilities, and is often used to match groups on non-verbal reasoning.

Standard short-term memory skills were assessed with the sub-tests of Digit Span (Wechsler, 1997): Digit Forward and Digit Backward. Digit Forward requires immediate oral repetition of orally presented sequences of digits, and Digit Backward requires immediate oral repetition of orally presented sequences of digits in reversed order.

\section{Reading measures}

We used three measures of reading proficiency: single word reading, pseudo-word reading, and paragraph reading. The lists of real words and pseudo-words were standard lists (Deutsch \& Bentin, 1996), presented with diacritics, which make Hebrew orthography transparent. Reading in context was assessed by reading a four-paragraph academic-level text in Hebrew (standardized for students by our lab; Ben-Yehudah, Sackett, Malchi-Ginzberg, \& 


\section{STM IN MUSICIANS AND DYSLEXIA}

Ahissar, 2001). Participants were instructed to read the text aloud, as quickly and accurately as possible, but slow enough to be able to answer a simple content question at the end, in order to encourage text comprehension. Both accuracy and rate (i.e. total number of words read in one minute) were scored for all reading tests.

Stimuli - estimating syllabic frequency

The exact frequency of syllables in Hebrew has not been calculated, probably because syllables cannot be automatically parsed from written Hebrew without vowel diacritics. We therefore assessed syllable frequency by calculating the distribution of syllables in the largest publicly available corpus of spoken Hebrew that has a phonological transcript ( 6,500 word tokens; The Corpus of Spoken Israeli Hebrew - CoSIH). In this corpus about 54\% percent of the syllables are CV, $25 \% \mathrm{CVC}$, and only $5.5 \% \mathrm{VC}$. The mean (SD) \% of occurrence in the corpus for the specific syllables that were used in the current study is $0.58(0.69)$ for the CV syllables and $0.11(0.11)$ for the VC syllables, $\mathrm{t}=6.8, \mathrm{p}<10-8$.

Procedure

We used a Syllable Span protocol (Oganian \& Ahissar, 2012; Weiss, Granot, \& Ahissar, 2014) which is based on the Digit Span protocol (WAIS-III; Wechsler, 1997), and administered it four times: with frequent (CV) and infrequent (VC) syllables, with and without series repetition. VC syllables were constructed by switching the vowel and the consonant phoneme in each CV syllable, e.g. $k o$ and $o k$. In the no-repetition condition, no syllable was repeated throughout the experiment. In the repeated condition we used two sequences that were gradually elongated and were presented in an interleaved manner. For example, the four initial sequences for the CV repeated condition were: 1. /ve/ /tsu/ 2. /ko/ / $\mathrm{a} / \mathbf{3}$. /ve//tsu/ /pi/ 4. /ko/ / $\mathrm{a} / / \mathrm{hu} / ;$ and for the non-repeated condition: 1. /tsu//na/ 2. / $\mathrm{e} / / \mathrm{ko} /$ 3. /li/ / $\mathrm{u} / / \mathrm{ga} / 4$. /di/ /bu/ /mo/. 


\section{STM IN MUSICIANS AND DYSLEXIA}

The VC spans were always administered before the CV spans, in order to avoid a possible benefit for the VC syllables due to training. The order of repetition vs. no-repetition was counter-balanced across participants. A recording of a native female Hebrew speaker was used; syllables were played at a fixed interval of 1 second (SOA). The score for each condition is the number of sequences which the participant reproduced correctly.

Participants

Participants were recruited through ads posted at the Hebrew University campuses, two other colleges in Jerusalem, and the Jerusalem Academy of Music and Dance. Participants were paid for their participation. Candidate participants filled in a detailed questionnaire about their formal academic education, history of reading difficulties (including previous diagnoses), musical background and medical condition. Exclusion criteria were: hearing problems, psychiatric medications other than attention deficit medication, and formal musical background for control and IDDs (i.e. more than 2 years of either playing a tonal instrument or formal singing education). All participants received all their schooling in Israel. Individuals who passed this preliminary screening were invited to a basic assessment session of cognitive and reading skills. On the basis of their performance in this session, one participant with dyslexia and one control participant were excluded due to below average cognitive scores (i.e. Block Design score < 7; Wechsler, 1997). One IDD had accurate (100\% correct) non-word reading, and was therefore excluded from the study. The dyslexic group included 8 participants who typically take medicine for ADHD (e.g., Concerta). Based on our previous studies (Ben-Yehudah et al., 2001) they were not excluded from participation, but they did not take medicine on test days.

Thirty-four control individuals, 35 IDDs and 37 musicians took part in Experiment 1. All members of the musician cohort were either students at the Jerusalem Academy of Music and Dance or professional musicians with an academic degree in music. Data of participants 


\section{STM IN MUSICIANS AND DYSLEXIA}

whose score was less than 3 in any of the span conditions were removed from the results, as we attribute their poor performance to lack of understanding of the task $(n=1)$; the 3 oldest control participants and the 7 youngest musicians were excluded in order to match age with the other groups. Thus, we report results of 31 controls, 34 IDDs and 30 musicians matched for age and general reasoning, as shown in Table 1. As expected, there was a significant difference in reading and reading related measures. In addition, consistent with previous findings (e.g. Ackerman, Dykman, \& Gardner, 1990; Torgesen, Wagner, Simmons, \& Laughon, 1990), IDDs' scores were significantly lower than those of controls and musicians in the Digit Span task.

Table 1

\begin{tabular}{|c|c|c|c|}
\hline & Controls & IDDs & Musicians \\
\hline Measure & $\mathrm{N}=31(13 \mathrm{M})$ & $\mathrm{N}=34(11 \mathrm{M})$ & $\mathrm{N}=30(9 \mathrm{M})$ \\
\hline Years of musical practice & Up to 2 & Up to 2 & $12.7(3.7)$ \\
\hline$\overline{\text { Age (years) }}$ & $25.16 \mathrm{a}(2.2)$ & $24.32 \mathrm{a}(3.1)$ & $24.27 \mathrm{a}(2.2)$ \\
\hline$\overline{\text { Block design (scaled) }}$ & $12.71_{\mathrm{a}}(3.0)$ & 12.91a (2.7) & $13.73 \mathrm{a}(2.6)$ \\
\hline Digit Span (scaled) & $11.32 \mathrm{a}(2.8)$ & $7.88 \mathrm{~b}(1.9)$ & $12.13 \mathrm{a}(3.0)$ \\
\hline $\begin{array}{l}\text { Single words reading } \\
\text { accuracy }(\% \text { correct) }\end{array}$ & 96.91a (4.2) & $87.25 \mathrm{~b}(8.0)$ & 99.17a (1.7) \\
\hline $\begin{array}{l}\text { Single words reading rate } \\
\text { (words/minute) }\end{array}$ & 96.6a (29.5) & $69.27 \mathrm{~b}(25.0)$ & $119.71 \mathrm{c}(22.5)$ \\
\hline $\begin{array}{l}\text { Pseudo-words reading } \\
\text { accuracy (\% correct) }\end{array}$ & $90.46 a(11.2)$ & $60.78 \mathrm{~b}(18.5)$ & 96.53a (3.6) \\
\hline $\begin{array}{l}\text { Pseudo-words reading rate } \\
\text { (words/minute) }\end{array}$ & $57.82 \mathrm{a}(24.2)$ & $33.67 \mathrm{~b}(11.9)$ & $76.26 \mathrm{c}(13.9)$ \\
\hline $\begin{array}{l}\text { Paragraph reading } \\
\text { accuracy }(\% \text { correct) }\end{array}$ & $98.65 \mathrm{a}(1.4)$ & $95.02 \mathrm{~b}(4.3)$ & $98.85 \mathrm{a}(1.1)$ \\
\hline $\begin{array}{l}\text { Paragraph reading rate } \\
\text { (words/minute) }\end{array}$ & 138.83a $(21.0)$ & $98.69 \mathrm{~b}(22.6)$ & $134.09 a(15.9)$ \\
\hline
\end{tabular}

Means (SD) are presented. M - Male participants.

Means with different superscript $(a, b, c)$ significantly differ at the $\mathrm{p}<0.05$ level after Bonferroni correction. 


\section{STM IN MUSICIANS AND DYSLEXIA}

\section{Results}

The number of correctly reproduced sequences in each condition (score; Table 2) was analyzed using a mixed-design analysis of variance (ANOVA) with Syllable Type (frequent vs. infrequent) and Repetition (repeated vs. non-repeated) as within-subject factors, and Group (controls, IDDs, and musicians) as a between-subject factor.

Table 2

\begin{tabular}{llllll}
\hline $\begin{array}{l}\text { Type of } \\
\text { syllable }\end{array}$ & $\begin{array}{l}\text { Type of } \\
\text { sequence }\end{array}$ & Measure & Controls & IDDs & Musicians \\
\hline \multirow{4}{*}{ Frequent } & Non-repeated & Score & $8.4(1.5)$ & $7.1(1.5)$ & $10.6(2.3)$ \\
\cline { 2 - 6 } & Repeated & Span & $5.6(1.0)$ & $5.0(0.9)$ & $7.2(1.4)$ \\
\cline { 2 - 6 } & Score & $10.6(2.2)$ & $9.1(2.2)$ & $13.2(2.1)$ \\
\cline { 2 - 6 } Infrequent & Span & $7.1(1.2)$ & $6.3(1.2)$ & $8.3(1.0)$ \\
\cline { 2 - 6 } & \multirow{2}{*}{ Non-repeated } & Score & $5.9(1.1)$ & $5.0(1.2)$ & $6.5(1.2)$ \\
\cline { 2 - 6 } & Repeated & Span & $4.2(0.6)$ & $3.9(0.7)$ & $4.8(0.8)$ \\
\cline { 3 - 6 } & & Score & $5.5(1.2)$ & $5.3(1.3)$ & $6.6(2.3)$ \\
\cline { 3 - 6 } & Span & $4.3(0.7)$ & $4.2(0.8)$ & $4.9(1.3)$ \\
\hline
\end{tabular}

Scores and spans (mean (SD)) of the Syllable Span task with frequent and rare syllables, with and without sequence repetition. The score for each sequence was either 0 or 1: 0 if there was at least one mistake/missing syllable, and 1 if the recall was perfect. The total score for each subject for each condition is the sum of the sequences' scores. The span is the length of the longest sequence which the participant was able to recall correctly.

The main effects were as expected: musicians achieved higher scores than controls, and controls achieved higher scores than IDDs (main effect of Group, $\mathrm{F}_{(2,92)}=33.18$, $\mathrm{p}<10$ 10, $\eta 2=.419$; a post hoc analysis with the Bonferroni correction: controls vs. IDDs: $p<.013$, controls vs. musicians: $\mathrm{p}<10-5$; Figure 2; Table 2). Scores for frequent syllables were higher than for infrequent ones (main effect of Syllable Type, $F_{(1,92)}=762.3, p<10-45, \eta 2=.892$; Figure 2) in each of the groups (controls: $d=3.82, S E=.26, p<10-25$; IDDs: $d=3.0, S E=$ $.25, p<10-20$, musicians: $d=5.37, S E=.26, p<10-25)$.

In line with our hypothesis, musicians benefited from syllable frequency more than controls, and controls benefited more than IDDs (Syllable Type X Group interaction, $F_{(2,92)}=$ 


\section{STM IN MUSICIANS AND DYSLEXIA}

22.2, $p<10-7, \eta 2=.325$; a one-tailed post hoc analysis on the difference between scores for frequent and for infrequent syllables with Bonferroni correction: controls vs. IDDs: $p<.034$, controls vs. musicians: $\mathrm{p}<10-4$; Figure 2). Additionally, group difference was larger for frequent $(\mathrm{CV})$ than for infrequent (VC) syllables (CV syllables - Controls vs. IDDs: $d=1.35$, $S E=.43, p<.007$, Musicians vs. Controls: $d=2.45, S E=.45, p<10-6$, Musicians vs. IDDs: $d=3.80, S E=.44, p<10-12$; VC syllables - Controls vs. IDDs: $d=.53, S E=.29, p=.203$, Musicians vs. Controls: $d=.91, S E=.29, p<.009$, Musicians vs. IDDs: $d=1.43, S E=.29, p<10-5$; Bonferroni corrected for multiple comparisons).

Repeated sequences yielded higher scores than non-repeated sequences (main effect of Repetition, $F_{(1,92)}=67.6, p<10-11, \eta 2=.424$; Figure 3; Table 2) in each of the groups (controls: $d=.89, S E=.24, p<10-3$; IDDs: $d=1.15, S E=.23, p<10-5$, musicians: $d=$ $1.37, S E=.25, p<10-6)$. But in contrast to the group difference in benefits from syllable frequency, the three groups did not significantly differ in their benefits from sequence repetition (Repetition X Group interaction: $F_{(2,92)}=.98, p=.380, \eta 2=.021$; Figure 3).

The benefit from repetition was larger for the frequent $\mathrm{CV}$ than for infrequent VC syllables (Syllable Type X Repetition interaction: $F_{(1,92)}=67.1, p<10-11, \eta 2=.422$ ). In fact, repetition effect was significant for the frequent $(d=2.26, S E=.20, p<10-18)$, but not the infrequent syllables $(d=.01, S E=.19, p=.947)$. Overall, the pattern of the benefit from repetition as a function of syllable frequency did not significantly differ between the groups (Syllable Type X Repetition X Group interaction: $\mathrm{F}(2,92)=1.25, \mathrm{p}<.291, \eta 2=.027$; controls: benefit from repetition for frequent syllables $d=2.19, S E=.35, p<10-7$, and for infrequent $d$ $=-0.42, S E=.33, p=.207$; IDDs: benefit from repetition for frequent syllables $d=1.97, S E$ $=.33, p<10-7$, and for infrequent $d=.32, S E=.32, p=.307$; musicians: benefit from repetition for frequent syllables $d=2.60, S E=.36, p<10$-10, and for infrequent $d=.13, S E$ $=.34, p=.692)$. 


\section{Benefit from syllable frequency: \\ musicians benefit more than controls, who benefit more than IDDs}

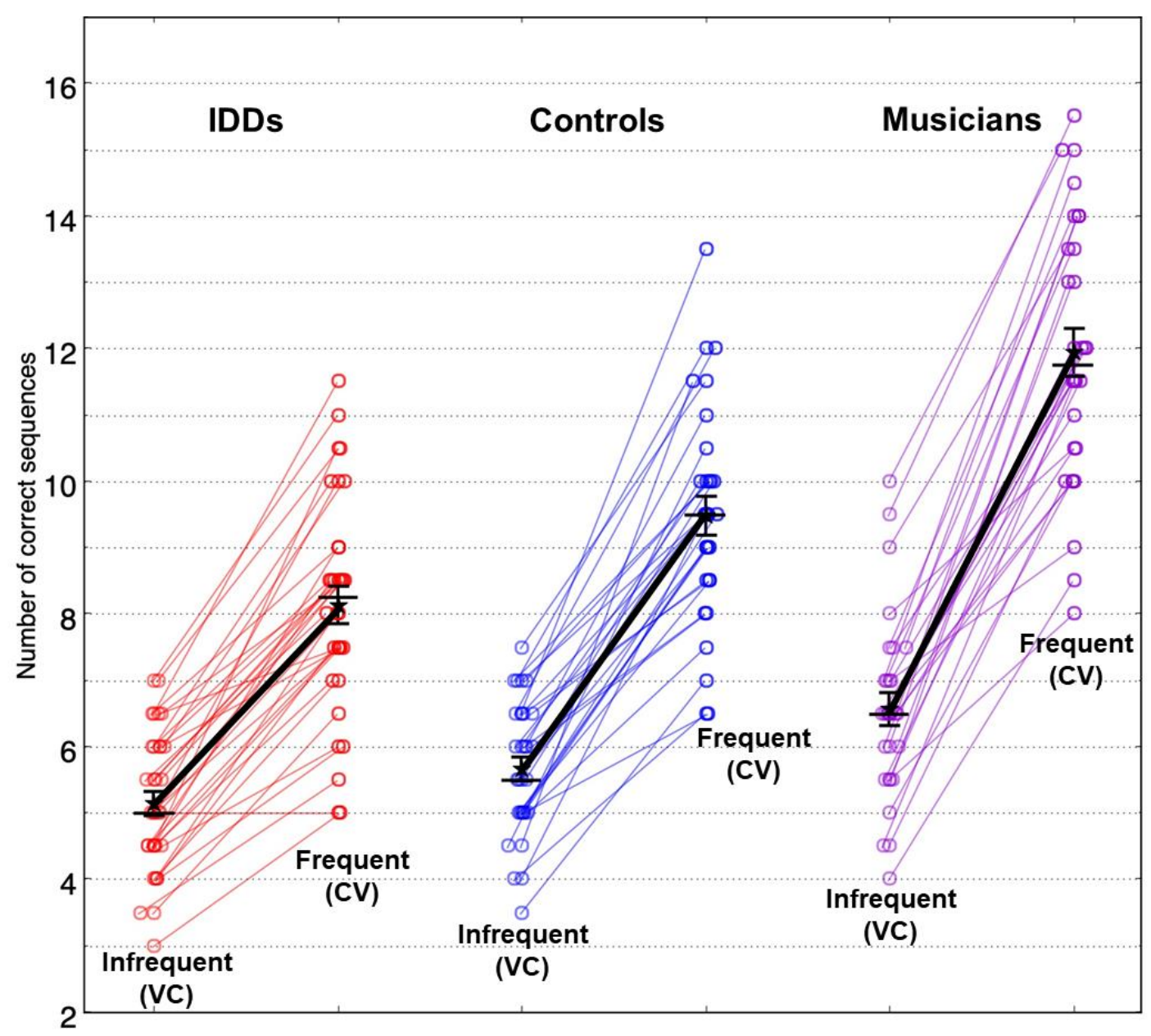

Figure 2. Scores of infrequent (VC) versus frequent (CV) syllable spans in the three test groups: IDDs (red), controls (blue), and musicians (violet). Groups are plotted (left to right) according to their increasing benefits from syllabic frequency. Spans are larger for frequent than for infrequent syllables (long-term frequency effect). Circles denote individual scores. Star symbols denote means; error bars denote 1 SEM; horizontal bars denote medians. 


\section{Benefits from series repetition: no significant group difference}

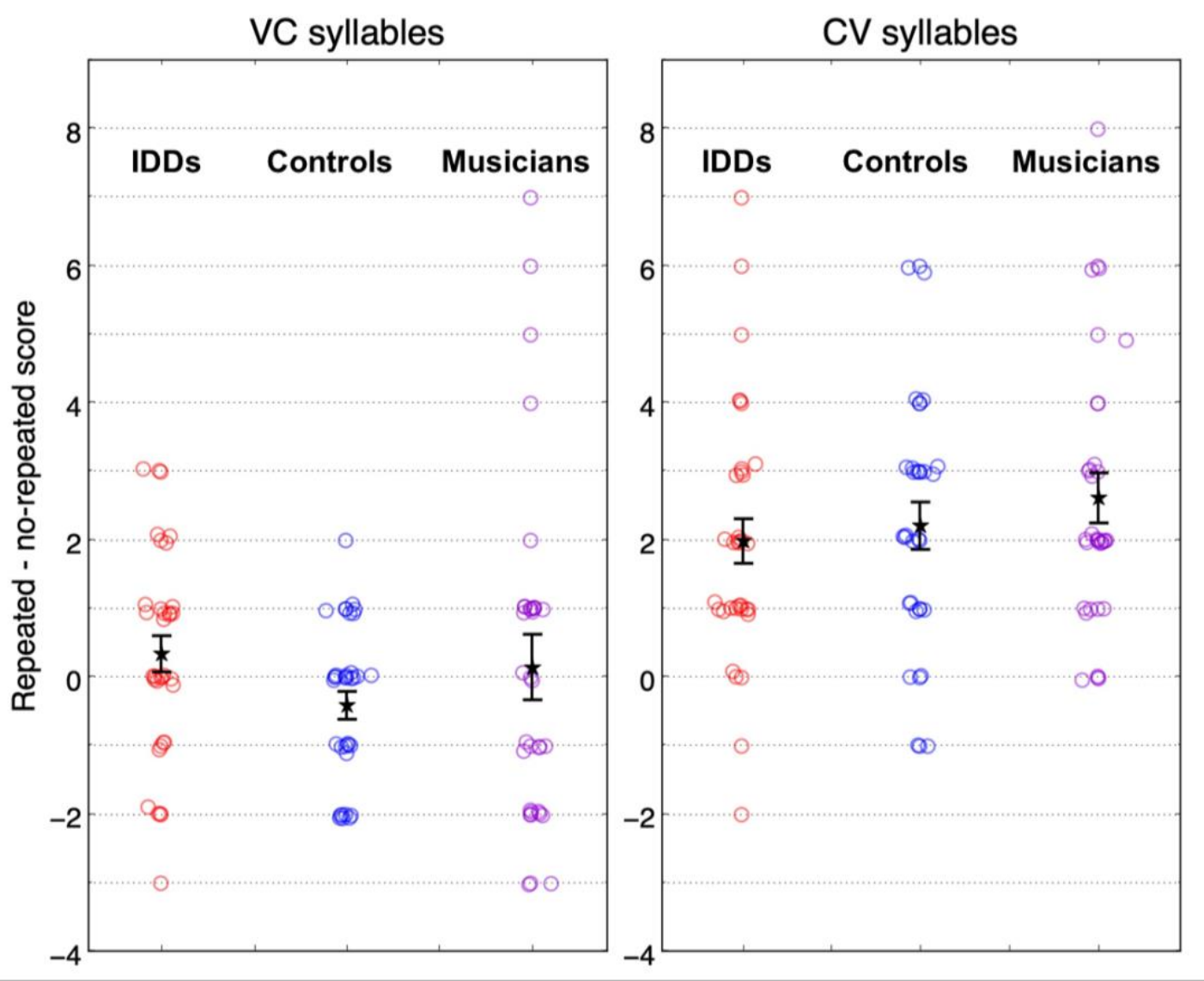

Figure 3. Difference between scores for spans with repeated series and spans without repeated series in sequences of infrequent $(\mathrm{VC}$, left) and frequent $(\mathrm{CV}$, right) syllables, in the three groups: IDDs (red), controls (blue), and musicians (violet). Benefit from series repetition does not significantly differ between the three populations, and is larger for $\mathrm{CV}$ syllables (right) than for VC syllables (left). Circles denote individual scores. Star symbols denote means; error bars denote 1 SEM; horizontal bars denote medians. 
STM IN MUSICIANS AND DYSLEXIA

\section{Discussion}

Overall the three groups showed the expected larger spans for lists composed of frequent (CV) vs. those composed of infrequent (VC) syllables, but IDDs' gain from syllable frequency was smaller than controls', and musicians' gain was greater than controls. Our results, taken together with the typical use of frequent stimuli in STM assessments, suggest that the reports on musicians' enhanced STM and IDDs' reduced STM stem to a large extent from musicians' enhanced and IDDs' reduced use of long-term statistics. By contrast, the benefits of IDDs and musicians from sequence repetition did not significantly differ from controls', suggesting that the benefits from series repetition do not differ between groups, and do not explain the difference in spans.

The group differences in item frequency benefit, together with their similar benefit from sequence repetition, suggest a dissociation between benefit from long-term item frequency and learning of a repeated sequence. In all three groups the benefit from sequence repetition was larger for $\mathrm{CV}$ than for $\mathrm{VC}$ sequences. This difference seems puzzling - if benefit from serial-order repetition does not depend on item familiarity, as suggested from the no group-difference in serial-order repetition, what other difference underlies the larger advantage of CVs compared with VCs in sequence repetition? A likely candidate is the "chunkability" of these two types of syllables, associated with their different manner of articulation, rather than their different degrees of familiarity. Thus it is easier to join the CV syllables to "chunks", increasing the effective STM (Miller, 1956). More formally, CVs are categorized as "light syllables" whereas VC are categorized as "heavy syllables" (Duanmu, 2010; Lunden, 2011), based on their different type of ending (rime). Heavy syllables attract stress (the Weight-Stress Principle, Duanmu, 2010; Velupillai, 2012) and a word (or a chunk of syllables) can only have one primary stress. Therefore, a sequence of VCs tends to be perceived and articulated with a stress on each syllable, supporting segmentation rather than 


\section{STM IN MUSICIANS AND DYSLEXIA}

chunking, since stressed syllables are treated as word onsets (Cutler \& Norris, 1988). By contrast, a sequence of CVs can be perceived and articulated as a long (chunked) multisyllabic word.

Based on the results of Experiment 1, we propose that there is a group difference in sensitivity to the frequency of syllables, but there is no significant group difference in the sensitivity to series repetition, since effective learning of repeated series relies mainly on syllable "chunkability", and the ability to chunk does not differ between the groups. To test this hypothesis, we conducted Experiment 2. The aim of this experiment was to test the dissociation between benefits from syllable frequency and syllable "chunkability" in a group that has adequate sensitivity to frequency, but reduced familiarity with the CV syllables. For this group we predicted reduced spans, but similar benefits from series repetition.

\section{Experiment 2}

CV syllables constitute the majority of syllables in Hebrew (Ben-Dror, Frost, \& Bentin, 1995), but their prevalence in English is substantially lower (28-38\%, Dauer, 1983). Based on this substantial difference, we now hypothesized that native English speakers (whose familiarity with Hebrew is only basic) would show reduced CV spans compared with native Hebrew speakers (as illustrated in Figure 1 - left side vs. right side). We further hypothesized that, in spite of their reduced spans, their benefits from serial-order repetition of these CV syllables would be similar to those of native Hebrew speakers, since their "chunkability", underlying the main benefits from repetition, is not based on familiarity but on their manner of articulation. We reasoned that such a dissociation would directly indicate the lack of dependence of benefits from series repetition on familiarity with the composing items, contrasting it with the dependence of STM on familiarity with the test items. 


\section{Method}

Participants

Native English speakers without reading difficulties were recruited through ads put at the school of international students of the Hebrew University. All recruited participants took Hebrew as a second language class, and their familiarity with Hebrew was only basic. We applied similar inclusion criteria as for the Hebrew-speaking controls (e.g. no learning difficulties and musical education of up to 2 years). Additionally, the data of the youngest English speaking participant were removed in order to match age across the groups. Thus, the control group of Experiment 1 and the native English speakers groups were matched for age, general reasoning skills (based on the same criteria) and scaled Digit Span scores in their native language (Table 3).

Data of participants whose score was $<3$ in one of the span conditions were removed from the results due to our attribution of their poor performance to misunderstanding of the task; data of one English speaking participant was consequently excluded. Participants for whom the difference between the conditions with and without repetition was smaller than their group mean by more than 2.5 standard deviations were defined as outliers, and were removed from the analysis; one additional English speaking participant was consequently excluded (for this participant the difference was -4). Thus, we report the results of 29 English speaking controls.

Procedure

We used the same procedure as in Experiment 1, and administered it twice using CV syllables with and without repetition (Oganian \& Ahissar, 2012; Weiss et al., 2014). The order of repetition vs. no-repetition was counter-balanced across participants. In order to have English-like syllables, a recording of a native female English speaker with native English articulation was used. 
bioRxiv preprint doi: https://doi.org/10.1101/795385; this version posted October 7, 2019. The copyright holder for this preprint (which was

not certified by peer review) is the author/funder, who has granted bioRxiv a license to display the preprint in perpetuity. It is made available under aCC-BY-NC-ND 4.0 International license.

STM IN MUSICIANS AND DYSLEXIA

Table 3

\begin{tabular}{llll}
\hline \multirow{2}{*}{ Measure } & $\begin{array}{l}\text { Hebrew-speaking } \\
\text { Controls }\end{array}$ & $\begin{array}{l}\text { English-speaking } \\
\text { Controls }\end{array}$ & \multirow{2}{*}{$\mathrm{t}$-value } \\
\cline { 2 - 3 } & $\mathrm{N}=31(13 \mathrm{M})$ & $\mathrm{N}=29(15 \mathrm{M})$ & $\mathrm{t}=1.55^{\wedge}$ \\
\hline Age (years) & $25.2(2.2)$ & $23.6(2.2)$ & $\mathrm{t}=1.64^{\wedge}$ \\
\hline Block design (scaled) & $12.7(3.0)$ & $11.6(2.6)$ & $\mathrm{t}=-0.43^{\wedge}$ \\
\hline $\begin{array}{l}\text { Native language Digit } \\
\text { Span (scaled) }\end{array}$ & $11.3(2.8)$ & $11.6(3.0)$ &
\end{tabular}

Means (SD) are presented. $\mathrm{M}-$ Male participants. ${ }^{\wedge}$ - n.s.

\section{Results}

The number of correctly reproduced sequences in each condition (score) was analyzed using a mixed-design analysis of variance (ANOVA) with Syllable Frequency (frequent vs. infrequent) and Repetition (repeated vs. non-repeated) as within-subject factors, and Group (controls, IDDs, musicians, and English speaking controls) as a between-subject factor. For Hebrew-speaking controls, IDDs and musicians, a subset of the data collected in Experiment 1 (CV syllables only) is reanalyzed in Experiment 2.

As expected, scores of English-speaking controls for the CV syllables were lower than those of Hebrew speaking controls, in spite of their matched Digit Span scores in their native language (Table 3). Their CV spans were even lower than Hebrew speaking IDDs' (main effect of Group: $F(3,120)=55.73, p<10-21, \eta 2=.582$; Bonferroni Post Hoc tests: IDDs vs. English speaking controls: $d=1.51, S E=.42, p<.003$; Figure 4). As expected, scores for repeated sequences were higher than for non-repeated (main effect of Repetition: $F_{(1,120)}=$ 154.17, $p<10-22, \eta 2=.562$; Figure 4). However, there was no difference in the effect of repetition between the groups (Repetition X Group: $F_{(3,120)}=1.76, p=.159, \eta 2=.042$; Bonferroni Post Hoc tests were all non-significant, for example, musicians vs. English speaking controls: $d=1.08, S E=.48, p=.160$; Figure 4). 


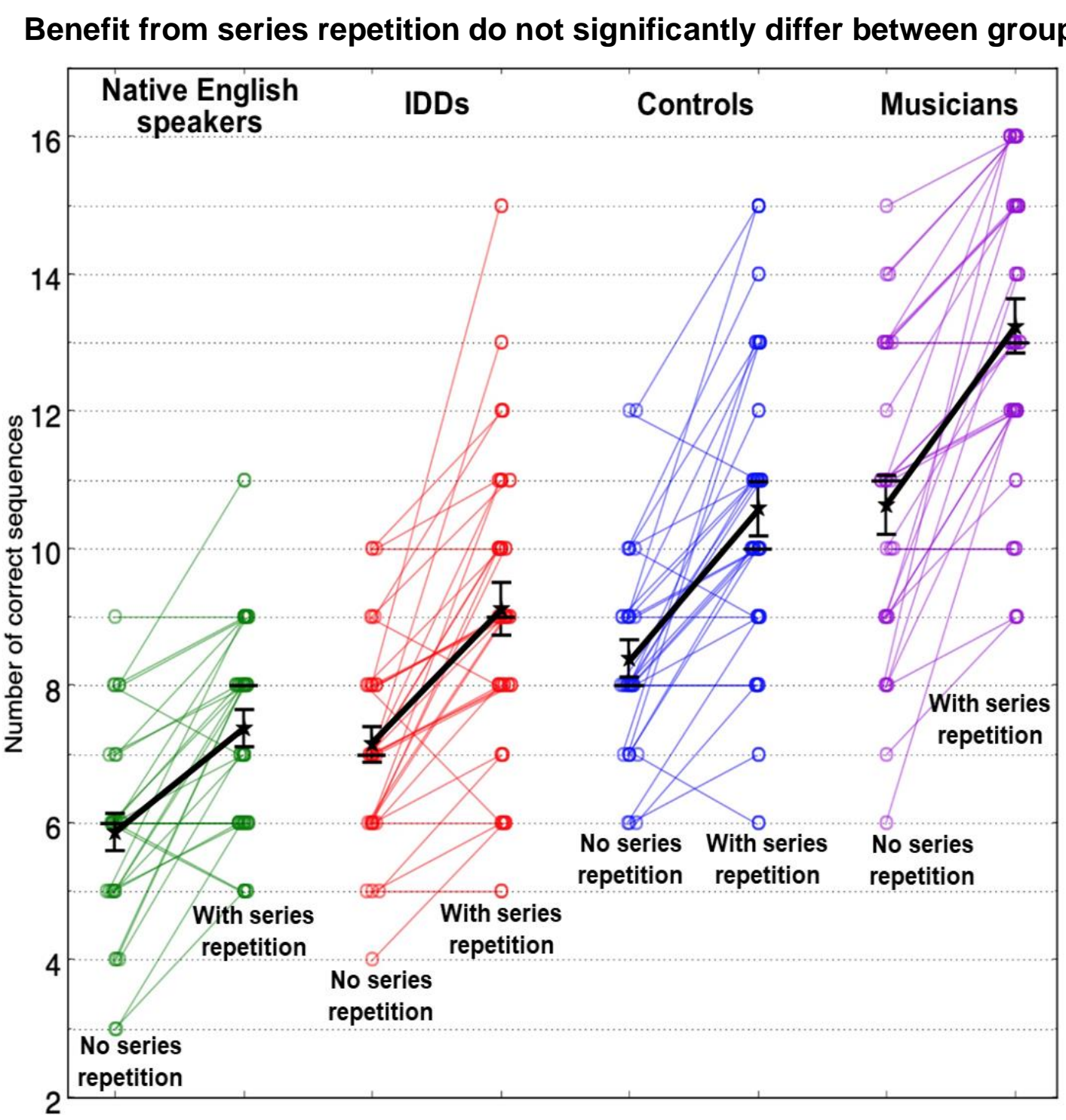

Figure 4. Spans of CV syllables, with and without series repetition: 4 populations with different degrees of exposure (Hebrew versus English speakers) and different sensitivity to item frequency (IDDs, controls. and musicians) differ in absolute scores but not in the benefits from series repetitions.

CV span scores of native English speakers (green), native Hebrew-speaking IDDs (red), controls (blue), and musicians (violet). For each participant: left - without repetition, and right with repetition. Spans of musicians are larger than controls', which are larger than IDDs'. Spans of all Hebrew speakers are larger than of English speakers. However, benefits from series repetition do not significantly differ between the groups. Circles denote individual scores. Star symbols denote means; error bars denote 1 SEM; horizontal bars denote medians. 
STM IN MUSICIANS AND DYSLEXIA

\section{Discussion}

As predicted, native English speakers, who are less familiar with CVs, had smaller CV spans than native Hebrew speakers. Yet, they did not significantly differ from Hebrew speakers in their benefit from series repetition of these syllables. These results support the hypothesis that the benefits due to series repetition, do not substantially rely on item frequency, beyond basic familiarity - the frequency of CV syllables is lower for native English speakers, and still their benefit from sequence repetition is comparable to native Hebrew speakers'.

\section{General Discussion}

In Experiment 1, we measured recall spans for infrequent (VC) syllables, and compared them to spans for frequent $(\mathrm{CV})$ syllables, with and without sequence repetition in three populations: Hebrew-speaking IDDs, controls and musicians. IDDs benefited from syllable frequency less than controls, and musicians benefited more than controls. However, the benefit in span for serial-order repeated series did not significantly differ between the groups. To further separate the factors underlying the benefit of familiarity from the factors underlying the benefit of serial-order repeated series we conducted Experiment 2. Native English speakers, less familiar with CV syllables, were administered the CV span task, with and without sequence repetition. Their scores were very poor, as expected. Yet, they showed a similar benefit from sequence repetition as was seen in Hebrew speakers.

The group difference in the benefit from syllable frequency sheds light on the mechanisms underlying IDDs' reduced, and musicians' enhanced, spans. Span tasks are usually performed using frequent items, and thus, it is likely that reports on reduced performance of IDDs and enhanced performance of musicians in fact rely to a large extent on reduced/enhanced benefit from item frequency. These results challenge the interpretation of span tasks as a basic measure of STM, and its implication that IDDs' reduced spans, and 


\section{STM IN MUSICIANS AND DYSLEXIA}

musicians' enhanced spans, indicate some unique STM properties. Importantly, they agree with recent imaging results suggesting that STM does not have representations separately from long-term memory, but rather reflects access to long-term memory (Sreenivasan, Curtis, \& D’Esposito, 2014).

By contrast, we found no significant difference in the benefit from series repetition between the groups. In the literature, the impact of sequence repetition on IDDs' performance is disputed (see Majerus \& Cowan, 2016 for a review). For example, a Hebb repetition learning paradigm (Hebb, 1961), in which a participant is exposed to a repeated sequence of syllables interleaved with non-repeated sequences, was previously administered to adult IDDs. While some studies reported that sequence learning poses a unique difficulty in dyslexia (Bogaerts et al., 2015; Szmalec et al., 2011), others failed to replicate this observation, in spite of using the same stimuli and analyses (Staels \& Van den Broeck, 2014, 2015). Our results suggest no deficit in serial-order learning among IDDs.

It has been previously suggested that musicians' enhanced STM might rely on enhanced general chunking skills, which are developed as part of the musical training (Talamini, Altoè, Carretti, \& Grassi, 2017). However, the generalization of musical training to enhanced chunking ability of untrained items is conceptually questionable given the specificity of benefits from training (Jakoby, Raviv, Jaffe-Dax, Lieder, \& Ahissar, 2019). Still, enhanced chunking skills may be associated with innate musical competence, or other characteristics of individuals who become musicians (Corrigall, Schellenberg, \& Misura, 2013). Given the lack of group difference in benefits from series repetition, our results do not support enhanced chunking in musicians.

Taken together, our results propose mirror skills of musicians and IDDs - enhanced versus reduced accumulation of stimuli statistics. Musician's enhanced reading skills have been characterized before (e.g. Weiss et al., 2014; early reading in children Anvari, Trainor, 


\section{STM IN MUSICIANS AND DYSLEXIA}

Woodside, \& Levy, 2002), and as such seem to mirror those of IDDs. However, the current study is the first that proposes, and shows, that for both populations, their unique STM characteristics can be explained by the same underlying mechanism, which affects their longterm representations.

Overall, a significant group difference in the benefit from item frequency alongside no significant group difference in the benefit from series repetition, suggest that these are driven by separate mechanisms. However, the two mechanisms interact following a large number of repetitions of a sequence. With abundant exposure, the repeated sequence becomes a new independent item (a stable long-term memory trace), which in turn can be used as part of a new sequence with other items (Reder, Paynter, Diana, Ngiam, \& Dickison, 2007), and enhance STM, which relies on extensive long-term knowledge (e.g. Nimmo \& Roodenrys, 2002). We found a significant group difference in the benefit from item frequency, but no significant group difference in the benefit from sequence repetition. Perhaps, manipulation of sequences does not differ between the groups, but when they are integrated and stored as independent units, the robustness of their representation, or the access to these representations, is reduced among IDDs and is enhanced among musicians.

\section{Acknowledgements}

This work was supported by the Canadian Institutes of Health Research, the International Development Research Center, the Israeli Science Foundation, and the Azrieli Foundation (grant No. 2425/15), and a personal grant from the Israel Science Foundation (grant No. 1650/17). Declarations of interest: none. 
STM IN MUSICIANS AND DYSLEXIA

\section{References}

Ackerman, P. T., Dykman, R. A., \& Gardner, M. Y. (1990). Counting Rate, Naming Rate, Phonological Sensitivity, and Memory Span: Major Factors in Dyslexia, 325-327. Ahissar, M. (2007). Dyslexia and the anchoring-deficit hypothesis. Trends in Cognitive Sciences, 11(11), 458-465. https://doi.org/10.1016/j.tics.2007.08.015

Ahissar, M., Lubin, Y., Putter-Katz, H., \& Banai, K. (2006). Dyslexia and the failure to form a perceptual anchor. Nature Neuroscience, 9(12), 1558-1564.

https://doi.org/10.1038/nn1800

American Psychiatric Association. (2013). Diagnostic and statistical manual of mental disorders (5th ed.). Arlington, VA: American Psychiatric Publishing.

Anvari, S. H., Trainor, L. J., Woodside, J., \& Levy, B. A. (2002). Relations among musical skills, phonological processing, and early reading ability in preschool children. Journal of Experimental Child Psychology, 83(2), 111-130. Retrieved from http://www.ncbi.nlm.nih.gov/pubmed/12408958

Banai, K., \& Ahissar, M. (2017). Poor sensitivity to sound statistics impairs the acquisition of speech categories in dyslexia. Language, Cognition and Neuroscience. https://doi.org/10.1080/23273798.2017.1408851

Ben-Dror, I., Frost, R., \& Bentin, S. (1995). Orthographic Representation and Phonemic Segmentation in Skilled Readers: A Cross-Language Comparison. Psychological Science, 6(3), 176-181. https://doi.org/10.1111/j.1467-9280.1995.tb00328.x

Ben-Yehudah, G., Sackett, E., Malchi-Ginzberg, L., \& Ahissar, M. (2001). Impaired temporal contrast sensitivity in dyslexics is specific to retain-and-compare paradigms. Brain, 124(7), 1381-1395. https://doi.org/10.1093/brain/124.7.1381

Bogaerts, L., Szmalec, A., Hachmann, W. M., Page, M. P. A., \& Duyck, W. (2015). Linking memory and language: Evidence for a serial-order learning impairment in dyslexia. 


\section{STM IN MUSICIANS AND DYSLEXIA}

Research in Developmental Disabilities, 43-44, 106-122.

https://doi.org/10.1016/j.ridd.2015.06.012

Chandrasekaran, B., \& Kraus, N. (2010). Music, Noise-Exclusion, and Learing. Music Preception, 297-306.

Chen, J. L., Penhune, V. B., \& Zatorre, R. J. (2008a). Listening to musical rhythms recruits motor regions of the brain. Cerebral Cortex (New York, N.Y. : 1991), 18(12), 28442854. https://doi.org/10.1093/cercor/bhn042

Chen, J. L., Penhune, V. B., \& Zatorre, R. J. (2008b). Moving on time: brain network for auditory-motor synchronization is modulated by rhythm complexity and musical training. Journal of Cognitive Neuroscience, 20(2), 226-239. https://doi.org/10.1162/jocn.2008.20018

Clements, G. N., \& Keyser, S. J. (1983). CV Phonology: A Generative Theory of the Syllable. Cambridge, Mass. : MIT Press. https://doi.org/10.2307/414790

Corrigall, K. A., Schellenberg, E. G., \& Misura, N. M. (2013). Music Training, Cognition, and Personality. Frontiers in Psychology, 4(April). https://doi.org/10.3389/fpsyg.2013.00222

Cowan, N. (2010). The magical mystery four: How is working memory capacity limited, and why? Current Directions in Psychological Science, 19(1), 51-57. https://doi.org/10.1177/0963721409359277

Crossman, E. R. F. W. (1959). A theory of the acquisition of speed-skill. Ergonomics, 2(2), 153-166. https://doi.org/10.1080/00140135908930419

Cutler, A., \& Norris, D. (1988). The Role of Strong Syllables in Segmentation for Lexical Access. Journal of Experimental Psychology: Human Perception and Performance, 14(1), 113-121. https://doi.org/10.1037/0096-1523.14.1.113

Dauer, R. M. (1983). Stress-timing and syllable-timing reanalyzed. Journal of Phonetics, 
STM IN MUSICIANS AND DYSLEXIA

$11(1), 51-62$.

Deutsch, A., \& Bentin, S. (1996). Attention factors mediating syntactic deficiency in readingdisabled children. Journal of Experimental Child Psychology, 63, 386-415.

Duanmu, S. (2010). Onset and the Weight-Stress Principle in English. In B. Hong, F. Wu, \& C. Sun (Eds.), Linguistic essays in honor of Professor Tsu-Lin Mei on his 80th birthday (pp. 295-338). Beijing: Capital Normal University Press.

Franklin, M. S., Sledge Moore, K., Yip, C. Y., Jonides, J., Rattray, K., \& Moher, J. (2008).

The effects of musical training on verbal memory. Psychology of Music, 36(3), 353-365. https://doi.org/10.1177/0305735607086044

Fujioka, T., Ross, B., Kakigi, R., Pantev, C., \& Trainor, L. J. (2006). One year of musical training affects development of auditory cortical-evoked fields in young children.

Brain : A Journal of Neurology, 129(Pt 10), 2593-2608.

https://doi.org/10.1093/brain/awl247

Gathercole, S. E., \& Adams, A. M. (1993). Phonological working memory in very young children. Developmental Psychology, 29(4), 770-778. https://doi.org/10.1037/00121649.29.4.770

Gathercole, S E, \& Baddeley, A. D. (1989). Evaluation of the role of phonological STM in the development of vocabulary in children: A longitudinal study. Journal of Memory and Language, 28(2), 200-213. https://doi.org/10.1016/0749-596X(89)90044-2

Gathercole, Susan E, Frankish, C. R., Pickering, S. J., \& Peaker, S. (1999). Phonotactic influences on short-term memory. Journal of Experimental Psychology: Learning, Memory, and Cognition, 25(1), 84-95. https://doi.org/10.1037/0278-7393.25.1.84

Heathcote, A., Brown, S., \& Mewhort, D. J. (2000). The power law repealed: the case for an exponential law of practice. Psychonomic Bulletin \& Review, 7(2), 185-207. https://doi.org/10.3758/BF03212979 
Hebb, D. (1961). Distinctive features of learning in the higher animal. In J. F. Delafresnaye (Ed.), Brain mechanisms and learning (pp. 37-46). Oxford: Blackwell.

Henderson, L. M., \& Warmington, M. (2017). A sequence learning impairment in dyslexia? It depends on the task. Research in Developmental Disabilities, 60, 198-210. https://doi.org/10.1016/j.ridd.2016.11.002

Hulme, C., Maughan, S., \& Brown, G. D. (1991). Memory for familiar and unfamiliar words: Evidence for a long-term memory contribution to short-term memory span. Journal of Memory and Language, 30(6), 685-701. https://doi.org/10.1016/0749-596X(91)90032-F Hulme, C., Roodenrys, S., Schweickert, R., Brown, G. D. A., Martin, S., \& Stuart, G. (1997). Word-Frequency Effects on Short-Term Memory Tasks : Evidence for a Redintegration Process in Immediate Serial Recall. Journal of Experimental Psychology: Learning, Memory, and Cognition, 23(5), 1217-1232.

Jaffe-Dax, S., Frenkel, O., \& Ahissar, M. (2017). Dyslexics' faster decay of implicit memory for sounds and words is manifested in their shorter neural adaptation. ELife, 6, 1-19. https://doi.org/10.7554/eLife.20557.001

Jaffe-Dax, S., Kimel, E., \& Ahissar, M. (2018). Shorter cortical adaptation in dyslexia is broadly distributed in the superior temporal lobe and includes the primary auditory cortex. ELife, 7, 1-9. https://doi.org/10.7554/eLife.30018

Jaffe-Dax, S., Raviv, O., Jacoby, N., Loewenstein, Y., \& Ahissar, M. (2015). A

Computational Model of Implicit Memory Captures Dyslexics' Perceptual Deficits. The Journal of Neuroscience, 35(35), 12116-12126.

https://doi.org/10.1523/JNEUROSCI.1302-15.2015

Jakoby, H., Raviv, O., Jaffe-Dax, S., Lieder, I., \& Ahissar, M. (2019). Auditory Frequency Discrimination Is Correlated With Linguistic Skills, but Its Training Does Not Improve Them or Other Pitch Discrimination Tasks. Journal of Experimental Psychology: 


\section{STM IN MUSICIANS AND DYSLEXIA}

\section{General, (March). https://doi.org/10.1037/xge0000573}

Janata, P., \& Grafton, S. (2003). Swinging in the brain: shared neural substrates for behaviors related to sequencing and music. Nature Neuroscience, 6(7), 682-687.

Janata, P., Tillmann, B., \& Bharucha, J. J. (2002). Listening to polyphonic music recruits domain-general attention and working memory circuits, 2(2), 121-140.

Jeffries, S., \& Everatt, J. (2004). Working memory: Its role in dyslexia and other specific learning difficulties. Dyslexia, 10(3), 196-214. https://doi.org/10.1002/dys.278

Kimel, E., \& Ahissar, M. (2019). Benefits From Morphological Regularities in Dyslexia Are Task Dependent. Journal of Experimental Psychology: Learning Memory and Cognition. https://doi.org/10.1037/xlm0000717

Lee, Y., Lu, M., \& Ko, H. (2007). Effects of skill training on working memory capacity. Learning and Instruction, 17(3), 336-344.

https://doi.org/10.1016/j.learninstruc.2007.02.010

Liberman, I. Y., Shankweiler, D., Fischer, F. W., \& Carter, B. (1974). Explicit syllable and phoneme segmentation in the young child. Journal of Experimental Child Psychology, 18(2), 201-212. https://doi.org/10.1016/0022-0965(74)90101-5

Lieder, I., Adam, V., Frenkel, O., Jaffe-Dax, S., Sahani, M., \& Ahissar, M. (2019). Perceptual bias reveals slow-updating in autism and fast-forgetting in dyslexia. Nature Neuroscience, 22, 256-264. https://doi.org/10.1038/s41593-018-0308-9

Lunden, S. L. A. (2011). The Weight of Final Syllables in English. In M. B. Washburn (Ed.), Proceedings of the 28th West Coast Conference on Formal Linguistics (pp. 152-159). Somerville, MA: Cascadilla Proceedings Project.

Luque, J. L., López-Zamora, M., Alvarez, C. J., \& Bordoy, S. (2013). Beyond decoding deficit: inhibitory effect of positional syllable frequency in dyslexic Spanish children. Annals of Dyslexia, 63(3-4), 239-252. https://doi.org/10.1007/s11881-013-0082-z 


\section{STM IN MUSICIANS AND DYSLEXIA}

Majerus, S., \& Cowan, N. (2016). The Nature of Verbal Short-Term Impairment in Dyslexia : The Importance of Serial Order. Frontiers in Psychology, 7, 1522. https://doi.org/10.3389/fpsyg.2016.01522

Miller, G. A. (1956). The Magical Number Seven, Plus or Minus Two Some Limits on Our Capacity for Processing Information. Psychological Review, 63, 81-97. https://doi.org/10.1037/h0043158

Morais, J., Cary, L., Alegria, J., \& Bertelson, P. (1979). Does awareness of speech as a sequence of phones arise spontaneously? Cognition, 7(4), 323-331. https://doi.org/10.1016/0010-0277(79)90020-9

Nimmo, L. M., \& Roodenrys, S. (2002). Syllable frequency effects on phonological shortterm memory tasks. Applied Psycholinguistics, 23(4), 643-659. https://doi.org/10.1017/S0142716402004071

Oganian, Y., \& Ahissar, M. (2012). Poor anchoring limits dyslexics' perceptual, memory, and reading skills. Neuropsychologia, 50(8), 1895-1905. https://doi.org/10.1016/j.neuropsychologia.2012.04.014

Parbery-Clark, A., Skoe, E., Lam, C., \& Kraus, N. (2009). Musician enhancement for speechin-noise. Ear and Hearing, 30(6), 653-661. https://doi.org/10.1097/AUD.0b013e3181b412e9

Perfetti, C. A., Beck, I., Bell, L. C., \& Hughes, C. (1987). Phonemic knowledge and learning to read are reciprocal: A longitudinal study of first grade children. Merrill-Palmer Quarterly, 283-319.

Ramus, F. (2014). Neuroimaging sheds new light on the phonological deficit in dyslexia. Trends in Cognitive Sciences, 18(6), 274-275. https://doi.org/10.1016/j.tics.2014.01.009 Ramus, F., \& Szenkovits, G. (2008). What phonological deficit? The Quarterly Journal of Experimental Psychology, 61(1), 129-141. https://doi.org/10.1080/17470210701508822 


\section{STM IN MUSICIANS AND DYSLEXIA}

Reder, L. M., Paynter, C., Diana, R. A., Ngiam, J., \& Dickison, D. (2007). Experience is a double-edged sword: A computational model of the encoding/retrieval trade-off with familiarity. Psychology of Learning and Motivation, 48, 271-312. https://doi.org/10.1016/S0079-7421(07)48007-0

Rispens, J., Roeleven, S., \& Koster, C. (2004). Sensitivity to subject-verb agreement in spoken language in children with developmental dyslexia. Journal of Neurolinguistics, 17(5), 333-347. https://doi.org/10.1016/j.jneuroling.2003.09.001

Roodenrys, S., Hulme, C., Lethbridge, A., Hinton, M., \& Nimmo, L. M. (2002). Wordfrequency and phonological-neighborhood effects on verbal short-term memory. Journal of Experimental Psychology: Learning, Memory, and Cognition, 28(6), 1019-1034. https://doi.org/10.1037//0278-7393.28.6.1019

Roodenrys, S., \& Stokes, J. (2001). Serial recall and nonword repetition in reading disabled children. Reading and Writing, 14, 379-394. https://doi.org/10.1023/A:1011123406884

Schiff, R., \& Ravid, D. (2007). Morphological analogies in Hebrew-speaking university students with dyslexia compared with typically developing gradeschoolers. Journal of Psycholinguistic Research, 36(3), 237-253. https://doi.org/10.1007/s10936-006-9043-6

Share, D. L., \& Blum, P. (2005). Syllable splitting in literate and preliterate Hebrew speakers: onsets and rimes or bodies and codas? Journal of Experimental Child Psychology, 92(2), 182-202. https://doi.org/10.1016/j.jecp.2005.05.003

Shook, A., Marian, V., Bartolotti, J., \& Schroeder, S. R. (2013). Musical Experience Influences Statistical Learning of a Novel Language. American Journal of Psychology, 126(1), 95-104. https://doi.org/10.1016/j.freeradbiomed.2008.10.025.The

Snowling, M., Goulandris, N., Bowlby, M., \& Howell, P. (1986). Segmentation and speech perception in relation to reading skill: A developmental analysis. Journal of Experimental Child Psychology, 41(3), 489-507. https://doi.org/10.1016/0022- 
STM IN MUSICIANS AND DYSLEXIA

0965(86)90006-8

Snowling, M. J. (2000). Dyslexia (2nd ed.). Oxford, UK: Blackwell.

Snowling, Margaret J. (1981). Phonemic deficits in developmental dyslexia. Psychological Research, 43(2), 219-234. https://doi.org/10.1007/BF00309831

Sommer, B. A. (1970). An Australian Language without CV Syllables. International Journal of American Linguistics, 36(1), 57-58.

Sreenivasan, K. K., Curtis, C. E., \& D’Esposito, M. (2014). Revisiting the role of persistent neural activity during working memory. Trends in Cognitive Sciences, 18(2), 82-89. https://doi.org/10.1016/j.tics.2013.12.001

Staels, E., \& Van den Broeck, W. (2014). Order short-term memory is not impaired in dyslexia and does not affect orthographic learning. Frontiers in Human Neuroscience, 8, 732. https://doi.org/10.3389/fnhum.2014.00732

Staels, E., \& Van den Broeck, W. (2015). No Solid Empirical Evidence for the SOLID (Serial Order Learning Impairment) Hypothesis of Dyslexia. Journal of Experimental Psychology: Learning, Memory, and Cognition, 41(3), 650-669.

Stoel-Gammon, C. (1989). Prespeech and early speech development of two late talkers. First Language, 9, 207-224.

Szmalec, A., Loncke, M., Page, M. P. A., \& Duyck, W. (2011). Order or disorder? Impaired Hebb learning in dyslexia. Journal of Experimental Psychology: Learning, Memory, and Cognition, 37(5), 1270-1279. https://doi.org/10.1037/a0023820

Talamini, F., Altoè, G., Carretti, B., \& Grassi, M. (2017). Musicians have better memory than nonmusicians : A meta-analysis. PLoS ONE, 12(10), e0186773.

Torgesen, J. K., Wagner, R. K., Simmons, K., \& Laughon, P. (1990). Identifying Phonological Coding Problems in Disabled Readers: Naming, Counting, or Span Measures? Learning Disability Quarterly, 13(4), 236-243. 


\section{STM IN MUSICIANS AND DYSLEXIA}

https://doi.org/10.2307/1510350

Tremblay, P., Deschamps, I., Baroni, M., \& Hasson, U. (2016). Neural sensitivity to syllable frequency and mutual information in speech perception and production. NeuroImage, 136, 106-121. https://doi.org/10.1016/j.neuroimage.2016.05.018

Velupillai, V. (2012). Introduction to Linguistic Topology. John Benjamins Publishing.

Wang, X., Xuan, Y., \& Jarrold, C. (2016). Using a Process Dissociation Approach to Assess Verbal Short-Term Memory for Item and Order Information in a Sample of Individuals with a Self-Reported Diagnosis of Dyslexia. Frontiers in Psychology, 7, Article 208. https://doi.org/10.3389/fpsyg.2016.00208

Wechsler, D. (1997). WAIS-III administration and scoring manual, The Psychological Corporation, San Antonio, TX.

Weiss, A. H., Granot, R. Y., \& Ahissar, M. (2014). The enigma of dyslexic musicians. Neuropsychologia, 54, 28-40. https://doi.org/10.1016/j.neuropsychologia.2013.12.009 Wimmer, H. (1993). Characteristics of developmental dyslexia in a regular writing system. Applied Psycholinguistics, 14(1), 1-33. https://doi.org/10.1017/s0142716400010122 